\title{
Morphological, Cultural and Sclerotial Variability among Isolates of Rhizoctonia solani Causal Agent of Web Blight of Soybean
}

\author{
Lekhashree*, Pankaj Kumar Singh and R. K. Dantre
}

Department of Plant Pathology, College of Agriculture, IGKV, Raipur (C.G), India

*Corresponding author

K e y w o r d s
Rhizoctonia solani,
Web blight of
soybean, Isolates,
Morphological,
Cultural, Sclerotial,
Variability
Article Info
Accepted:
07 November 2019
Available Online:
10 December 2019

\section{A B S T R A C T}

In the present study morphological, cultural and sclerotial variability was observed among 17 isolates collected from five districts of Chhattisgarh. Lowest hyphal width was observed to be that of RS $10(2.16 \mu \mathrm{m})$ and highest hyphal width was observed to be that of RS $14(4.38 \mu \mathrm{m})$ the least angle of branching was observed to be that of RS $12\left(77.45^{\circ}\right)$ and the highest angle of branching was observed to be that of RS $5\left(95.743^{\circ}\right)$. Significant variation in distance between septa was also observed among the isolates (36.34 to 11.33 $\mu \mathrm{m})$. Based on the observation of colony colour the different isolates were assigned into three different groups i.e. pale white, light brown and ivory. The different isolates were assigned into four different groups i.e. sparse, sparse fluffy, cottony and cottony fluffy based on texture of the colony. The number of sclerotia formed ranged from zero to 112. The different isolates were classified into 4 groups on the basis of sclerotial pattern i.e. peripheral, centre, scattered and ring in the middle. The isolates were classified into smooth, rough, smooth pitted and rough pitted on the basis of sclerotia texture.

\section{Introduction}

Soybean is called "Golden Gift" of the nature to mankind due to its various uses. Since time immemorial, soybean has served as milk, cheese, bread as well as oil for the people of China and East Asia; and the ancient literature of these countries called it as "gold from soil". Off late, its versatility was recognized by the west, which called it "golden bean" or "miracle bean". Due to its immense potential as food, fodder, feed, fuel and industrial production; soybean is said to have revolutionized the agricultural economy of west, particularly of United States. USA, Brazil, Argentina, China and India are the top five countries in the world with respect to area and production. In Chhattisgarh major soybean growing districts are Rajnandgaon, Durg, Mungeli, Bemetara and Kabirdham. 
Soybean is mainly grown during Kharif season in sandy loam to clay loam soil in Chhattisgarh. Soybean plant is known to suffer from many diseases such as Rhizoctonia web blight, anthracnose, rust, Cercospora leaf spot, target spot, bud blight, yellow mosaic and some non-parasitic diseases due to excesses and deficiencies of trace elements (Sinclair, 1982). Among the fungal diseases Rhizoctonia web blight is one of the most important disease which attack the soybean plant towards maturity and directly affect on yield of soybean particularly in humid and warm part of the country and 35-60 percent yield losses have been estimated by Ray et al., (2007). Web blight disease is becoming a new problem for soybean crop in Chhattisgarh and occurs in severe form in all soybean growing areas of Chhattisgarh. The knowledge about this disease is very meagre. Keeping in view the wide occurrence of disease and its destructive nature present investigation "Morphological, cultural and sclerotial variability among isolates of Rhizoctonia solani causal agent of web blight of soybean" has been undertaken.

\section{Materials and Methods}

The present investigation was carried out at the Research farm and laboratory of Department of Plant Pathology, College of Agriculture, Indira Gandhi Krishi Vishwavidyalaya, Raipur.

\section{Collection of diseased sample}

An intensive survey was conducted during kharif 2016 in soybean growing districts of Chhattisgarh. The soybean leaves naturally infected with Rhizoctonia aerial blight symptoms were collected from the infected plants from farmers fields at different locations of Chhattisgarh (Rajnandgaon, Durg, Bemetra, Kabirdham and Raipur). Collected samples were brought to the laboratory for critical examination of the symptoms and identification and morpho-cultural variability studies. A total of 17 isolates of $R$. solani were obtained.

\section{Morphological variability}

Morphological characters like hyphal width, angle of hyphal branching and distance between two septa were examined for each isolate by using Olympus OSM Digital counter mounted on Olympus Vanox-S AHBS microscope.

\section{Cultural variability}

Isolates of $R$. solani were grown on fresh PDA medium plates at $27 \pm 2^{\circ} \mathrm{C}$ in incubator for studying colony characters such as colour of colony, colony texture,/appearance, radial growth.

\section{Sclerotial variability of $\boldsymbol{R}$. solani isolates}

Time taken for sclerotial formation, colour, weight, number, sclerotial pattern, sclerotia location, texture of sclerotia and honey dew secretions in petriplate of each isolate were recorded at regular intervals after incubation at $27 \pm 2^{\circ} \mathrm{C}$ in sterilized plates containing PDA medium. Munsell's colour chart was used to record the colour of the sclerotia. The sclerotial bodies placed on the sterilized glass slide and the key colour cards were kept side by side against white background under sunlight for comparison (Burpee et al., 1991).

\section{Results and Discussion}

\section{Morphological variability}

Among the 17 isolates the lowest hyphal width was observed to be that of RS 10 (2.16 $\mu \mathrm{m})$ and highest hyphal width was observed to be that of RS $14(4.38 \mu \mathrm{m})$ followed by RS 8 $(4.34 \mu \mathrm{m}), \mathrm{RS} 11(4.27 \mu \mathrm{m}), \mathrm{RS} 12(4.17 \mu \mathrm{m})$, 
RS $13(4.11 \mu \mathrm{m}), \mathrm{RS} 3(4.06 \mu \mathrm{m}), \mathrm{RS} 4(4.05$ $\mu \mathrm{m})$, RS $2(3.40 \mu \mathrm{m})$. They were statistically at par with each other. The observations were found to be in accordance with that of Kuiry et al.,(2014) who observed the hyphal width ranged from 2.25 to $13.08 \mu \mathrm{m}$. Among the 17 isolates the least angle of branching was observed to be that of RS $12\left(77.45^{\circ}\right)$ and the highest angle of branching was observed to be that of RS $5\left(95.743^{\circ}\right)$. Significant variation in distance between septa was also observed among the isolates (36.34 to $11.33 \mu \mathrm{m})$.

Isolate RS 4 was found significantly superior and formed higher distance between two septa $(36.34 \mu \mathrm{m})$ followed by RS $7(34.00 \mu \mathrm{m})$ which was at par with each other (Fig. 1).

\section{Cultural variability}

Based on the observation of colony colour the different isolates were assigned into three different groups i.e. pale white, light brown and ivory. Out of 17 isolates, 8 isolates were pale white in appearance. Five isolates were light brown in appearance. Four isolates were ivory in appearance. The results are in accordance with Lal and Kandhari (2009) who while studying variability of $R$. solani isolates found 6 isolates as light brown, five isolates were found yellowish brown, four isolates were whitish brown in colour, six isolates were dark brown and four isolates were very pale brown. Based on the observation of colony texture the different isolates were assigned into four different groups i.e. sparse, sparse fluffy, cottony and cottony fluffy.Out of 17 isolates, 6 isolates i.e. RS 7,RS 9, RS 10, RS 12, RS 14, RS 17 were sparse in appearance. Seven isolates i.e. RS 1,RS 2,RS 3, RS 5, RS 11, RS 13, RS 17 were sparse fluffy in appearance. Two isolates i.e. RS 4 and RS 15 were cottony in appearance. Two isolates i.e. RS 6 and RS 8 were cottony fluffy in appearance. The mycelial growth of the isolates varied from $21.6 \mathrm{~mm}$ (RS 5) to $54 \mathrm{~mm}$ (RS 15) after 24 hours. All the isolates except
RS $13(86.3 \mathrm{~mm})$ showed full growth $(90 \mathrm{~mm})$ after 48 hours). Lal and Kandhari (2009) reported that ten isolates covered the whole plate $(90 \mathrm{~mm})$ in 48 hours.

\section{Sclerotial variability}

The number of sclerotia formed ranged from zero to 112.The maximum number of sclerotia formed in RS 14 (112) followed by RS 8(110) which was statistically at par with each other. The number of sclerotia formed in five isolates were very high $(>100)$. The number of sclerotia formed in six isolates was high (51100). The number of sclerotia formed in RS 11 and RS 17 were moderate (26-50).

The number of sclerotia formed in RS 7 was low (1-25). The different isolates were classified into 4 groups on the basis of sclerotial pattern i.e. peripheral, centre, scattered and ring in the middle. It was seen that in eight isolates sclerotial arrangement was on surface i.e. aerial sclerotia was absent. Both aerial and surface sclerotia were observed in case of 8 isolates. Lal and Kandhari (2009) reported that in 15 isolates sclerotia were formed on surface of mycelium and 9 were both aerial and surface.

The different isolates were classified into 4 categories i.e. smooth, rough, smooth pitted and rough pitted on the basis of sclerotia texture. The majority of isolates were found to be rough pitted in nature. Three isolates were smooth pitted in nature. One isolate i.e. RS 10 was found to be rough in nature. Four isolates were found to be smooth in nature. The different isolates were grouped into 4 categories on the basis of sclerotia colour i.e. light brown, brown, dark brown and grey. Four isolates were light brown in colour. Four isolates were brown in colour. Seven isolates were found to be dark brown in colour i.e. One isolate was observed to be grey in colour (Fig. 2). 
Table.1 Cultural variability among different isolates

\begin{tabular}{|c|c|c|c|c|c|}
\hline Isolate & Colony colour & $\begin{array}{c}\text { Colony } \\
\text { texture/appearance }\end{array}$ & \multicolumn{3}{|c|}{$\begin{array}{c}\text { Mycelial } \\
\text { growth(mm/hours) }\end{array}$} \\
\hline & & & 24 & 48 & 72 \\
\hline RS 1 & Pale white & Sparse fluffy & 24.96 & 90.00 & - \\
\hline RS 2 & Pale white & Sparse fluffy & 27.60 & 90.00 & - \\
\hline RS 3 & Light & Sparse fluffy & 26.88 & 90.00 & - \\
\hline brown & & & & \\
\hline RS 4 & Light brown & Cottony & 31.20 & 90.00 & - \\
\hline RS 6 & Ivory & Sparse fluffy & 21.60 & 90.00 & - \\
\hline RS 7 & Ivory & Cottony fluffy & 40.38 & 90.00 & - \\
\hline RS 8 & Pale white & Sparse & 27.80 & 90.00 & - \\
\hline RS 9 & Pale white & Cottony fluffy & 43.44 & 90.00 & - \\
\hline RS 10 & Pale white & Sparse & 34.80 & 90.00 & - \\
\hline RS 11 & Light brown & Sparse & 37.20 & 90.00 & - \\
\hline RS 12 & Light brown & Sparse fluffy & 34.80 & 90.00 & - \\
\hline RS 13 & Light brown & Sparse & 37.20 & 90.00 & - \\
\hline RS 14 & Pale white & Sparse fluffy & 28.80 & 86.30 & 90.00 \\
\hline RS15 & Pale white & Sparse & 26.60 & 90.00 & - \\
\hline RS 16 & Ivory & Cottony & 54.00 & 90.00 & - \\
\hline RS 17 & Ivory & Sparse fluffy & 51.12 & 90.00 & - \\
\hline
\end{tabular}

Table.2 Sclerotial variability among different isolates

\begin{tabular}{|c|c|c|c|c|c|c|c|c|c|}
\hline \multicolumn{7}{|c|}{ Sclerotia Weight Sclerotia Sclerotial Arrangement Sclerotia Sclerotia Honeydew } \\
\hline Isolate initiation (mg) (No/plt) pattern surface/aerial texture colour Formation (hrs) \\
\hline RS 1 & 48 & 21.50 & 85 & Peripheral & Surface & Rough pitted & Dark brown & No \\
\hline RS 2 & 72 & 10.46 & 82 & Centre & Both & Smooth pitted & Light brown & No \\
\hline RS 3 & 72 & 26.34 & 105 & Peripheral & Surface & Rough pitted & Brown & No \\
\hline RS 4 & 72 & 23.96 & 73 & Peripheral & Both & Rough pitted & Dark brown & No \\
\hline RS 5 & 72 & 25.25 & 108 & Scattered & Surface & Rough pitted & Dark brown & No \\
\hline RS 6 & 48 & 22.14 & 102 & Scattered & Both & Smooth pitted & Dark brown & No \\
\hline RS 7 & 48 & 25.60 & 14 & Scattered & Both & Rough pitted & Brown & No \\
\hline RS 8 & 48 & 19.61 & 110 & Scattered & Both & Smooth & Light brown & No \\
\hline RS 9 & 48 & 22.40 & 91 & Peripheral & Both & Smooth & Brown & No \\
\hline RS 10 & 48 & 15.18 & 63 & Peripheral & Both & Rough & Brown & No \\
\hline RS 11 & 48 & 21.39 & 38 & Scattered & Both & Smooth & Light brown & No \\
\hline RS 12 & - & - & - & - & - & & - & - \\
\hline RS 13 & 72 & 24.73 & 41 & Centre & Surface & Smooth & Dark brown & No \\
\hline RS 14 & 72 & 26.94 & 112 & Peripheral & Surface & Rough pitted & Dark brown & No \\
\hline RS 15 & 72 & 26.99 & 101 & Peripheral & Surface & Rough pitted & Dark brown & No \\
\hline RS 16 & 72 & 25.37 & 66 & Ring in & Surface & Rough pitted & Light brown & No \\
\hline RS 17 & 72 & 27.78 & 27 & Centre & Surface & Smooth pitted & Grey & Yes \\
\hline SE (m) \pm & 0.573 & 0.950 & & & & & \\
\hline CD(5\%) & 1.723 & 2.741 & & & & & \\
\hline
\end{tabular}


Fig.1 Morphological variability among different isolates

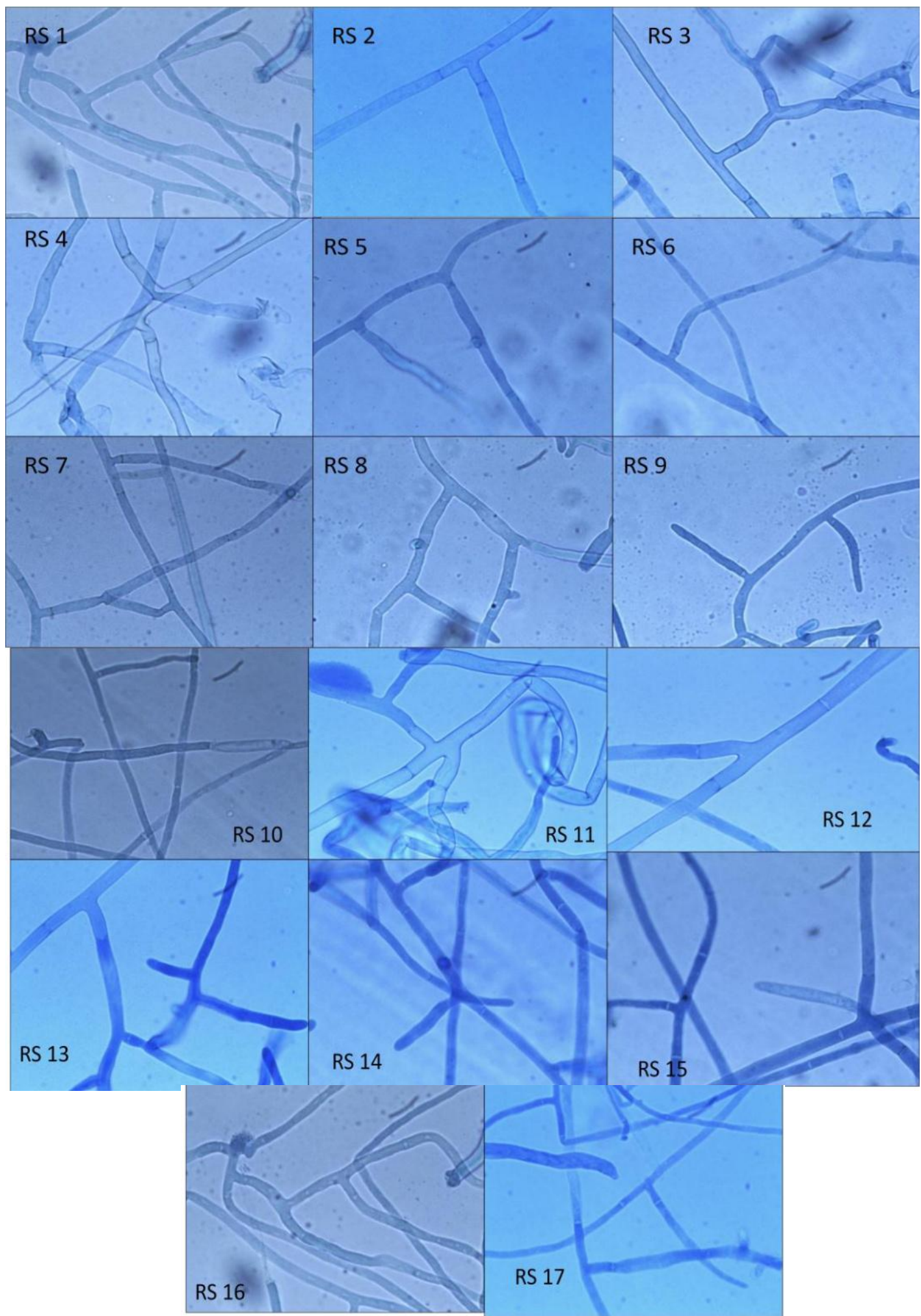


Fig.2 Different isolates of $R$. solani collected from survey

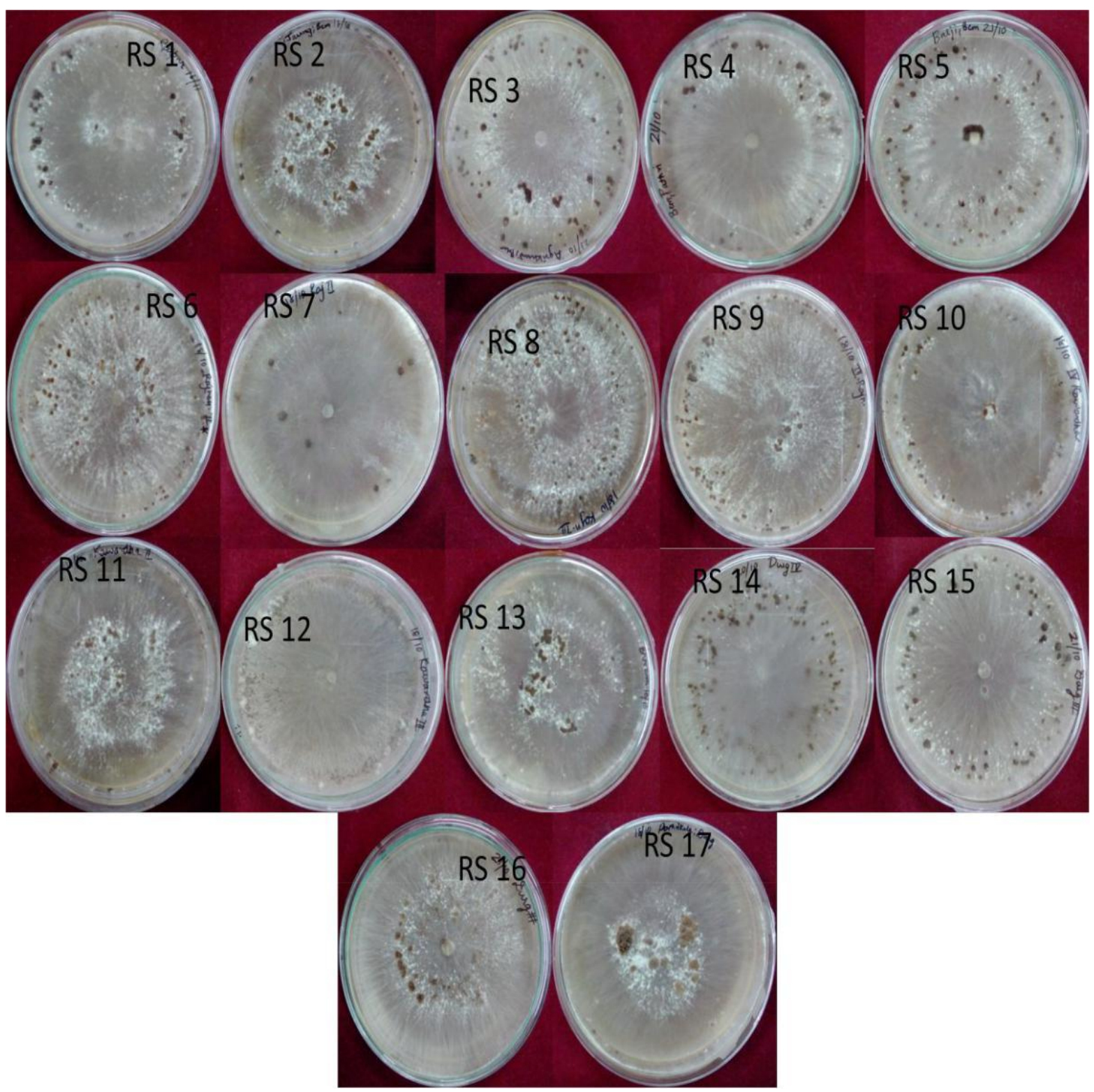

The sclerotial weight ranged from $10.46 \mathrm{mg}$ to $27.78 \mathrm{mg}$. Maximum sclerotial weight was recorded in RS $17(27.78 \mathrm{mg})$. The minimum sclerotial weight was recorded in RS 2(10.46 $\mathrm{mg})$. In case of seven isolates sclerotia initiation was found to occur after 48 hours whereas in case of nine isolates sclerotia initiation was found to occur after 72 hours. Honeydew formation was observed in only 1 isolate i.e. RS 17 while in the other isolates honeydew formation was not seen.
It was observed that all the isolates covered the entire plate $(90 \mathrm{~mm})$ after 48 hours except RS 13 (86.30 mm). Eight isolates were found pale white, five isolates light brown and four isolates were ivory in colony colour. Seven isolates were sparse fluffy, six isolates were sparse, two isolates were cottony and two were cottony fluffy in colony texture. The highest hyphal width $(4.38 \mu \mathrm{m})$ was recorded in case of RS 14 which was followed by RS 8.The highest angle of branching was 
observed for RS $5\left(95.743^{\circ}\right)$ and least for RS $12\left(77.45^{\circ}\right)$. The highest distance between two septa was recorded in case of RS $4(36.34 \mu \mathrm{m})$ and least for RS $14(11.33 \mu \mathrm{m})$. Seven isolates showed sclerotia initiation after 48 hours while nine isolates showed sclerotia initiation after 72 hours. The highest sclerotial weight $(27.87 \mathrm{mg}$ ) was recorded for RS 17. The highest number of sclerotia (112) was observed in RS 14, followed by RS 8(110). Eight isolates were found to be rough pitted, three were smooth pitted, four were smooth and one was rough in terms of sclerotial texture. Seven isolates were dark brown, four isolates were light brown, four isolates were brown and one was grey in terms of sclerotia colour. The sclerotial arrangement pattern of seven, three, five and one isolate was peripheral, central, scattered and ring in middle respectively. Honeydew formation was not observed in all the isolates except RS 17.

\section{Acknowledgement}

The authors are thankful to the Department of Plant Pathology, IGKV, Raipur for providing the necessary facilities for conducting the research. A special word of thanks for Professor Dr. R.K. Dantre for his guidance and support throughout the work.

\section{References}

Sneh, B., Burpee, L. and Ogoshi, A. 1991. Identification of Rhizoctonia species. APS

Kuiry, S.P., Mondal, A., Banerjee,S. and Dutta, S. 2014. Morphological variability in Rhizoctonia solani isolates from different agro-ecological zones of West Bengal, India. Archives of Phytopathology and Plant Protection, 47(6): 728-736.

Ray, A., Kumar, P. and Tripathi, H.S. 2007. Evaluation of bio-agents against Rhizoctonia solani Kühn the cause of aerial blight of soybean. Indian Phytopath., 60 (4): 532-534.

Sinclair, J.B. 1982. Compendium of soybean diseases. American Phytopathol. Society, pp: 27-28.

\section{How to cite this article:}

Lekhashree, Pankaj Kumar Singh and Dantre, R. K. 2019. Morphological, Cultural and Sclerotial Variability among Isolates of Rhizoctonia solani Causal Agent of Web Blight of Soybean. Int.J.Curr.Microbiol.App.Sci. 8(12): 652-658.

doi: https://doi.org/10.20546/ijcmas.2019.812.085 